\title{
Estimation Production Function of Inpatient Services and Input Productivity: A Cross-Sectional Study of Iran Selected Public Hospitals
}

\author{
Hamid Mohammadi ${ }^{1}$, Mohammad Meskarpour-Amiri ${ }^{2,3, *}$ \\ ${ }^{1}$ Allameh Tabataba'i University, Tehran, IR Iran \\ ${ }^{2}$ Health Management Research Center, Baqiyatallah University of Medical Sciences, Tehran, IR Iran \\ ${ }^{3}$ Tarbiat Modares University, Tehran, IR Iran
}

*Corresponding Author: Mohammad Meskarpour-Amiri, Ph.D. Student of Health Economics, Tarbiat Modares University, Tehran, IR Iran. Tel: +98-21-82482476, Fax: +98-21-82482476, Email: mailer.amiri@ gmail.com

Received: 7 Mar. 2016; Accepted: 3 May. 2016; Online Published: 27 Aug. 2016

\begin{abstract}
Background: Optimal allocation of resources commensurate with performance improvement is the concerns of all countries including Iran. Estimation hospitals production function is important in the economic management of hospitals.

Objective: The aim of this study was to estimate the production function of Iranian selected public hospitals as well as analyze the economic behavior in use of hospital resources.

Methods: The study was conducted by using the input data of 67 Iranian selected public hospitals at 2013. In this study, expected production level of hospitals and marginal productivity of inputs were calculated by regression estimation of Cobb-Douglas production function.

Results: The results showed that a $10 \%$ increase in net working hours of specialized human resources in public hospitals would cause $8.8 \%$ increase in average production level of inpatient services. Moreover, $10 \%$ increase of active beds would cause $1.1 \%$ increase in average production level of inpatient services in the studied hospitals. Also, the production levels in $40 \%$ of hospitals were lower than the average expected production level and did not have full performance.

Conclusion: With the proper utilization of human resources and beds, production level in a significant number of hospitals can be improved.
\end{abstract}

Keywords: Hospitals, Inpatients, Efficiency

\section{Background}

The health-care sector has been one of the most important sub-sectors of the services sector whose performance is an indicator of development and social welfare of a country. In most developing countries, 5 to $10 \%$ of government expenditure is allocated to this sector $[1,2]$. Among the various components of the health-care sector, hospital services are the most common cause of cost growth in many countries and in the public sector, this growth has been much faster when compared to other sectors [3]. According to an extensive study of the World Bank on public hospitals, hospitals' consumption share of public sector health resources in developing countries is between 50 to $80 \%$ [4]. In Iran, more than $6.4 \%$ of GDP belongs to health costs and about $40 \%$ of government health spending is associated with hospital cares, at least half of which is financed directly by households out-of-pocket [4]. Despite the importance role of hospitals in health care costs, few studies have been carried out on the economics of hospitals in developing countries [5].

One of the interesting topics in most developing countries including Iran is the utilization of healthcare resources and proper allocation of resources in the health sector. According to the Iran National Health Accounts, in 2007, total healthcare costs (as a part of GDP) were 145 trillion Rials in current prices $[4,6]$. Generally, in the hospitals, the medical personnel and physical facilities and equipment, are the key factors of service production [6]. Combination of these inputs according to the average level of technology utilized by them has remarkable changes during the last ten years.
The hospital should employ economic analysis to ensure optimum utilization of resources and its production facilities. Using economic principles and subsequently, evaluation of the economic performance of the service provider organizations, shall cause the correction of process and the continuity of measures and provides economic management of hospital industry - as the most costly sector [7, 8]. One of the economic tools is production function of hospitals that actually shows the optimal combination of production resources for hospital services [9].

\section{Objective}

Estimated production function of public hospitals can make a good understanding of economic management situation of these hospitals in Iran. Therefore, the aim of this study was to estimate the production function of inpatient services of Iranian public hospital and determine the hospital input productivity.

\section{Methods}

This study was a statistical-analytical study that was carried out, using information of inpatient services output as well as inputs of human resources and active beds capital, in public hospitals at 2013. The study population which involved 67 public hospitals, were randomly selected from a list of all public hospitals across the country. In terms of geographical distribution, the selected hospitals were located in all provinces except four provinces. Moreover, Tehran and Alborz provinces with 10 and 5 hospitals respectively had the highest number of selected hospitals. 
To calculate the marginal production of specialized manpower and capital of active beds in each hospital, CobbDouglas production function was employed. Cobb-Douglas production function in this study is illustrated in the following equation:

$$
\mathrm{Q}_{\text {inpatient }}=\mathrm{A} * \mathrm{~K}^{\alpha} * \mathrm{~L}^{\beta}
$$

Where $\mathrm{Q}_{\text {inpatient }}=$ number of inpatients during a year as hospital production level of inpatient services

$\mathrm{K}=$ number of beds as input of capital

$\mathrm{L}=$ sum of doctors and assistants as specialized human resources

$\mathrm{A}=$ constant coefficient or technology coefficient

$\alpha$ and $\beta$ are considered as technical coefficients for the production factors of capital (beds) and specialized human resources in public hospitals. The sum of the coefficients $\alpha$ and $\beta$ are considered to be equal to 1 , which therefore was a first order homogeneous production function. To estimate the production function with OLS method, the general shape of the production function was logarithmic and it was estimated using the Eviews7 software.

$$
\operatorname{Ln} \mathrm{Q}=\operatorname{Ln} \mathrm{A}+\alpha * \operatorname{Ln} \mathrm{K}+\beta * \operatorname{Ln} \mathrm{L}
$$

Where $\mathrm{Q}_{\text {inpatient }}=$ hospital service production level

$\mathrm{K}=$ number of beds as input of capital

$\mathrm{L}=$ sum of doctors and assistants as specialized human resources

$A=$ constant coefficient or technology coefficient

\section{Results}

The result of estimation of production function for public hospitals demonstrated a significant relationship between the hospital service production level (number of inpatients per year), and production factors of human resources (L) and capital of bed $(\mathrm{K})(\mathrm{P}<0.05)$. The elasticity of inpatient service level in the public hospitals to specialized human resources and beds were 0.882 and 0.118 respectively. Based on this, $10 \%$ increase in net working hours of specialized human resources in public hospitals can causes $8.8 \%$ increase in average production levels of inpatient services. Also, $10 \%$ increase in the use of active beds would cause $1.1 \%$ increase in average production level of inpatient services in public hospitals. Table 1 shows the results of production function of inpatient services in the country's public hospital.

Table 1. Results of estimating the production function of public hospital inpatient services

\begin{tabular}{lcc}
\hline Model Variables & Coefficients & P value \\
\hline Constant value $(\operatorname{Ln} \mathbf{A})$ & 4.255 & 0.0000 \\
Logarithm of beds $(\boldsymbol{\alpha})$ & 0.118 & 0.0021 \\
Logarithm of human resources $(\boldsymbol{\beta})$ & 0.882 & 0.0001 \\
\hline & $\mathrm{R} 2=0.99$ & \\
\hline
\end{tabular}

Based on Table 1, the non-logarithmic and general form of the inpatient service production function can be written as follows:

$Q_{\text {inpatient }, i}=70.437 * K_{i}^{0.118} * L_{i}^{0.882} \quad i=1,2, \ldots, 67$

In the above equation, 0.118 and 0.882 are considered as technical coefficients of capital of the beds and specialized human resources respectively. In this equation, 70.437 is defined as the anti-log $\operatorname{of} \ln A=4.255$, while $e^{4.255}=$ 70.437 .
Given the number of human resources $\left(L_{i}\right)$ and beds $\left(K_{i}\right)$ in each hospital, comparison of the actual product of each hospital with expected production level for that hospital revealed that 26 of studied hospitals have had inpatient services less than the average expected production level, and did not have full performance.

Results of the comparison of marginal production or marginal input productivity as well as the comparison of elasticity or standard marginal productivity of these factors with their average levels are shown in Table 2.

Table 2. Hospitals status in productivity and efficiency

\begin{tabular}{lcc}
\hline Productivity and Efficiency Indicators & Number & Percentage \\
\hline $\begin{array}{l}\text { Hospitals with less than average } \\
\text { marginal productivity for human } \\
\text { resources }\end{array}$ & $\begin{array}{c}26 \\
\text { hospitals }\end{array}$ & 38.8 \\
$\begin{array}{l}\text { Hospitals with less than average } \\
\text { marginal productivity for beds }\end{array}$ & $\begin{array}{c}21 \\
\text { hospitals }\end{array}$ & 31.3 \\
$\begin{array}{l}\text { Hospitals with marginal less than } \\
\text { average productivity for both inputs of } \\
\text { human resources and beds }\end{array}$ & $\begin{array}{c}15 \\
\text { hospitals }\end{array}$ & 22.3 \\
\hline $\begin{array}{l}\text { Hospitals without full efficiency } \\
\text { hospitals }\end{array}$ & 38.8 \\
\hline
\end{tabular}

\section{Discussion}

The results revealed that in Iranian public hospitals, the elasticity of inpatient service level in terms of specialized human resources $(0.88)$ is higher than beds $(0.18)$. Based on this, the production of selected public hospitals in the country is most affected by the specialized manpower and reacts with more sensitivity to decrease and increase in specialized human resources rather than beds. The $10 \%$ increase in net working hours of specialized human resources (doctors and nurses), will increase the service production in country's public hospitals by $9 \%$. Previous studies have also emphasized the importance of skilled manpower in the inpatient services production. The investigation of economic behavior of Tehran's publiceducational hospitals by Rezapour and Khalaj also revealed that elasticity of inpatient service in terms of specialized human resources of doctors (0.58) and nurses (0.37) is higher than beds (0.36)[10]. Studying the production function of educational hospitals in Mashhad province, Mahboobi et al. also stated that the inputs of doctors, nurses, and beds with impact factors of $0.57,0.36$ and 0.24 respectively have the greatest impact on inpatient services production [6]. In addition, investigation of the production function of hospitals affiliated to Qazvin University of Medical Sciences by Rezapour and Asefzadeh also revealed that the inputs of doctors, nurses and active beds have the most impact on inpatients service delivery in the hospitals [11].

Based on the results obtained for the production function of the public hospitals, the marginal productivity of human resources in 26 hospitals and the marginal productivity of beds in 21 hospitals were less than the average marginal productivity of input. In addition, 15 hospitals were faced with marginal productivity less than average for both inputs. Thus, it can be concluded that 26 hospitals were faced with surplus specialized human resources, and 21 hospitals were faced with a number of inactive hospital beds, and 15 hospitals were faced with both the problem of excess human resources, and the inactivation of inpatient beds. Moreover, the comparison of actual production level of each hospital 
with expected production-based on the inputs used showed that 26 public hospitals in the country's hospitals have had inpatient services less than the average expected production level, and did not have full efficiency.

The evaluation of the productivity and efficiency of hospitals based on the ratio of the output data have been considered in past studies. The researches carried out by Ghaderi et al. [12] and Sajadi et al. [13] can be noted in which using data envelopment analysis (DEA), the efficiency of educational-medical centers and hospitals were assessed. Afzali et al. [14] in their study which was conducted using two techniques of simple ratio analysis and comprehensive data envelopment analysis, technical efficiency of Social Security hospitals was measured, results revealed that 22 of the 53 hospitals were efficient and inefficient hospitals had an average efficiency score of $78 \%$. Azar et al. in their study evaluated the efficacy of Tehran University of Medical Sciences hospitals using DEA. Results of the study revealed that only 8 of the 22 hospitals had full performance and 33 and $41 \%$ of excess beds and human sources exist in inefficient hospitals respectively [15].

\section{Conclusion}

Inpatient services in public hospitals are more sensitive to the input of specialized human resources than active beds. In addition, many of the studied public hospitals did not have full efficiency. It can be concluded that with the proper use of human resources and active beds, production levels in a significant number of hospitals can be increased.

\section{Acknowledgements}

We would like to thank the Shahed University for its spiritual support.

\section{Authors' Contributions}

All authors contributed equally to this research.

\section{Conflict of Interest}

There is no conflict of interest.

\section{References}

1. Ameryoun A, Meskarpour-Amiri M, Dezfuli-Nejad ML, KhoddamiVishteh H, Tofighi S. The assessment of inequality on geographical distribution of Non-cardiac intensive care beds in Iran. Iran J Public Health. 2011;40(2):25

2. Meskarpour-Amiri M, Mehdizadeh P, Barouni M, Dopeykar N, Ramezanian M. Assessment the trend of inequality in the distribution of intensive care beds in Iran: using GINI index. Glob J Health Sci. 2014;6(6):28. doi: 10.5539/gjhs.v6n6p28

3. Meskarpour-Amiri M, Arani AA, Sadeghi H, Agheli-Kohnehshahri L. Socioeconomic Factors Affecting Informal Payments in the Health Sector. Transylvanian Rev Adm Sci. 2016;12(47):116-28.

4. Ahmadi AM, Assari-Arani A, Meskarpour-Amiri M. Inequality of health spending and public health outcome in countries of the WHO's Eastern Mediterranean Regional Office (EMRO). Int J Travel Med Glob Health. 2015;3(4):137-41

5. Amerioun A, Sh T, Mahdavi S, Mamaghani H, Meskarpour Amiri M. Assessment of International Joint Commission (IJC) accreditation standard in a military hospital laboratory. J Mil Med. 2011;13(2):7580 .

6. Mahboobi AP, Meskarpour AM, Pakdaman M. Estimation of production function in hospitals of Mashhad University of Medical Sciences (1996-2008). J Qazvin Univ Med Sci. 2013;17(3):34-41.

7. Rapoport J, Teres D, Zhao Y, Lemeshow S. Length of stay data as a guide to hospital economic performance for ICU patients. Med Care. 2003;41(3):386-97. doi: 10.1097/01.MLR.0000053021.93198.96

8. Newhouse JP. Toward a theory of nonprofit institutions: An economic model of a hospital. Am Econ Rev. 1970;60(1):64-74.

9. Hellinger FJ. Specification of a hospital production function. Appl Econ. 1975;7(3):149-60. doi: 10.1080/00036847500000016

10. Rezapour A, Khalaj M. The economic behavior of general hospitals of Iran University of Medical Sciences from 1997 to 2004. Shahrekord Univ Med Sci J. 2006;8(3):11-6.

11. Rezapour A, Asefzadeh S. Estimating cost-function at hospitals of Qazvin University of Medical Sciences (2001-2005). J Qazvin Univ Med Sci. 2008;11(4):77-82.

12. Ghaderi H, Goudarzi R, Gohari M. Determine the technical efficiency Hospital University of Medical Sciences, using two analysis comprehensive data. J Health Manag. 2005;9(26):31-8.

13. Sajadi H, Karami M, Torkzadeh L, Karimi S, Bidram R. Efficiency estimation in general hospitals of Isfahan University of Medical Sciences during 2005-2006 by data envelopment analysis. J Health Admin. 2009;12(36):39-46.

14. Afzali HHA, Moss JR, Mahmood MA. A conceptual framework for selecting the most appropriate variables for measuring hospital efficiency with a focus on Iranian public hospitals. Health Serv Manag Res. 2009;22(2):81-91. doi: 10.1258/hsmr.2008.008020

15. Azar A. Evaluation of hospital efficiency by data envelopment analysis: Tehran University of Medical Sciences: 2009-2011. J Health Admin. 2013;16(53):36-46. 